\title{
Manufacturing of $\varnothing 1,000$ Grade Large Diameter Round Bloom and Development of Cost Effective Hot Forging Process Using the Round Bloom
}

\author{
Hisang Chang*, Jinmo Lee, Namyong Kim, Chaehun Lee, Sanghyun Heo, Sunryong Yoon, \\ Byeong Don Joo
}

Research and Development Center, Taewoong, Busan, Republic of Korea

Email address:

hisang.chang@taewoong.com (H. Chang)

*Corresponding author

\section{To cite this article:}

Hisang Chang, Jinmo Lee, Namyong Kim, Chaehun Lee, Sanghyun Heo, Sunryong Yoon, Byeong Don Joo. Manufacturing of Ø 1,000 Grade Large Diameter Round Bloom and Development of Cost Effective Hot Forging Process Using the Round Bloom. International Journal of Materials Science and Applications. Vol. 7, No. 1, 2018, pp. 28-32. doi: 10.11648/j.ijmsa.20180701.15

Received: December 1, 2017; Accepted: December 12, 2017; Published: January 17, 2018

\begin{abstract}
Taewoong is an open die forging company, specialized in the production of hot forged and ring rolled parts. Recently, Taewoong utilized continuous casting facilities that can manufacture Ø 1,000 grade large diameter round bloom to increase competitiveness of the company. This study focuses installed continuous casting facilities and ring rolling process using manufactured $\varnothing 1,000$ grade round bloom. Constitution of installed facilities was introduced and characteristics of the facilities, EAF (Electric Arc Furnace), LF (Ladle Furnace), VD (Vacuum Degassing), VOD (Vacuum Oxygen Decarburization) and CC (Continuous Casting) were described. Also, ring rolling experiments were performed using manufactured Ø 1,000 grade round bloom. Hot forging process design was performed to fabricate sound products. Work sequence design was performed using FE analysis software and optimal forging work sequence was derived. With the results, sound forged parts were formed and improvement of competitiveness was verified. Raw material recovery ratio was increased and the number of process and processing time were decreased. The results show utilized continuous cast facilities give opportunity to be a world competitive company by increasing competitiveness of the company.
\end{abstract}

Keywords: Continuous Casting, Ø 1,000 Grade, Large Diameter Round Bloom, Hot Forging, Ring Rolling, Cost Reduction

\section{Introduction}

Open die forging is a kind of metal forming process that making desired shape by hammering or pressing. In open die forging, raw material is not enclosed by dies and deforms to space where not contacted by dies. Open die forging has many advantages such as removal of internal defect, improved microstructure, finer grain size, continuous metal flow, increased fatigue and greater strength. Open die forged parts and seamless ring rolled parts are widely using for projects in the wind energy, chemical and petrochemical, ship building and marine engine, and power industries [1-4]. Taewoong is growing into one of the world's largest open die forging company, specialized in the production of hot forged parts and wide range of shapes and sizes can be fabricated with 6 open die forging presses (15,000 ton, 8,000 ton, 5,000 ton, 3,500 ton, 2,000 ton, 15,000 ton) and 2 ring rolling mills $(\varnothing 9,500, \varnothing$ $3,000)$. Recently, Taewoong utilized continuous casting facility nearby forging facility to increase competitiveness of the company by reducing processing cost. The total annual capacity of the facility is 300,000 ton of ingots and 400,000 ton of round blooms and various grades of carbon steels, alloy steels and stainless steels can be produced. The weight range of the ingot with and without VSD (Vacuum Stream Degassing) is from 80 ton to 500 ton and from 10 ton to 80 ton, respectively. The diameter range of the round bloom is from $310 \mathrm{~mm}$ to $1,000 \mathrm{~mm}$. This study introduces utilized continuous casting facilities to produce large diameter round bloom and hot forging process with the round bloom. 


\section{Continuous Casting Facilities}

Taewoong utilized facilities for continuous casting consists of EAF (Electric Arc Furnace), LF (Ladle Furnace), VD (Vacuum Degassing), VOD (Vacuum Oxygen Decarburization) and $\mathrm{CC}$ (Continuous Casting) to manufacture $\varnothing 1,000$ grade large diameter round bloom. Figure 1 shows continuous casting process for various steel grades. Carbon steels, alloy steels and tool steels are manufactured through EAF, LF, VD and CC. Especially, stainless steels fabricated through EAF, LF, VD/VOD and CC.

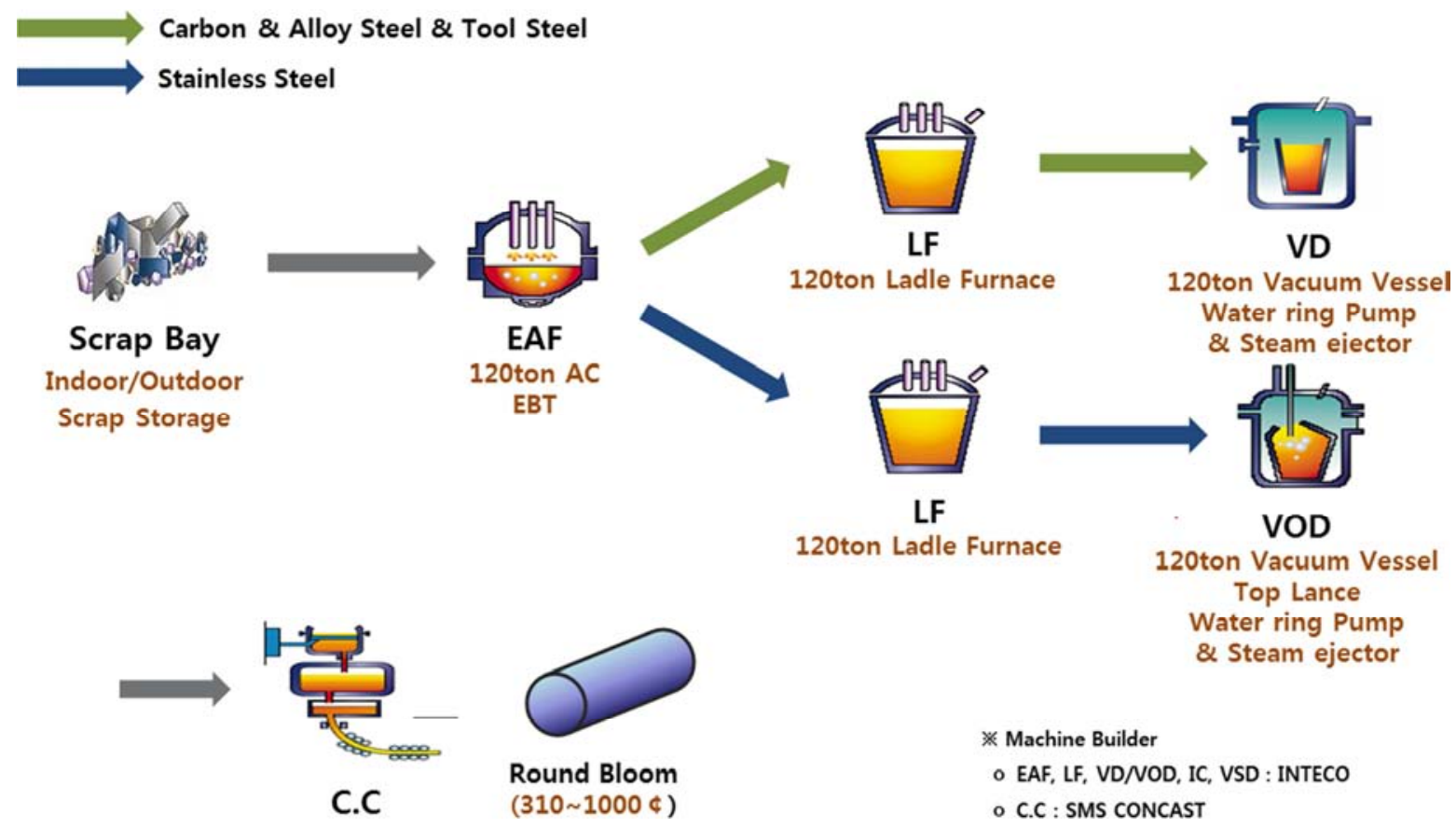

Figure 1. Continuous casting steel making process (Taewoong).

\subsection{EAF (Electric Arc Furnace)}

EAF with split shell type design supplied by INTECO is installed. Heat size of the furnace is 120 ton (Max. 150 ton) and AC (Alternating Current) electrical system and $120 \mathrm{MVA}$ transformer are adapted. The oxygen and carbon injection is done through front door and minimum tap-to-tap time and is about 50 minutes. Utilized EAF is shown Figure 2.

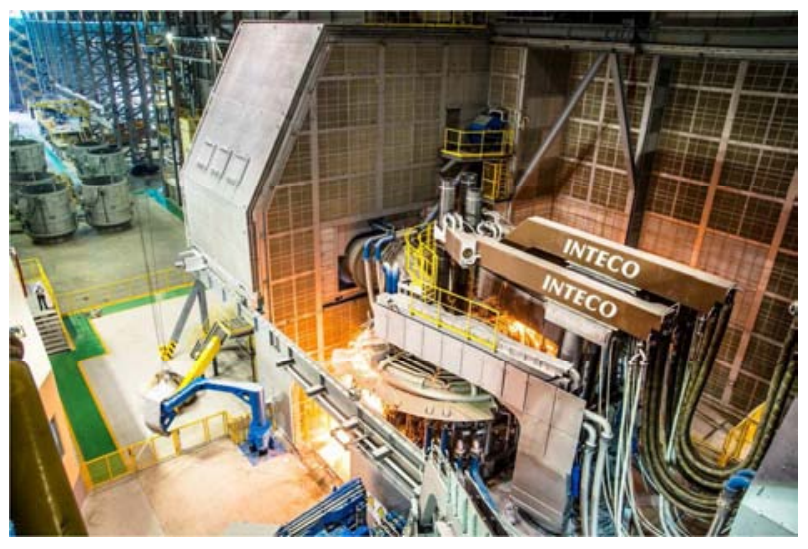

Figure 2. Electric arc furnace.

\subsection{LF (Ladle Furnace)}

Figure 3 shows installed LF that powered by 28 MVA transformer. Heat nominal of the furnace is 120 ton (Max. 150 ton). Material handling system of the furnace consist 36 alloy bins and auto gas coupling system is equipped. Also, the furnace has one wire feeding machine and two transfer cars.

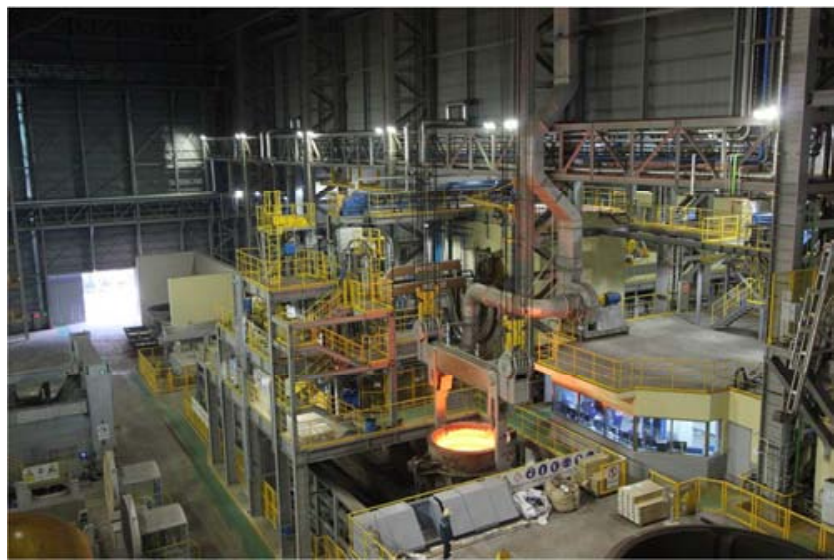

Figure 3. Ladle Furnace.

\subsection{VD / VOD (Vacuum Degassing / Vacuum Oxygen Decarburization)}

VD / VOD is shown in Figure 4. The degassing system consists of a VD / VOD vessel that uses watering pump and stream ejector to generate the required vacuum. One oxygen blowing lance and one wire feeding machine are equipped and auto gas coupling system is adapted. 


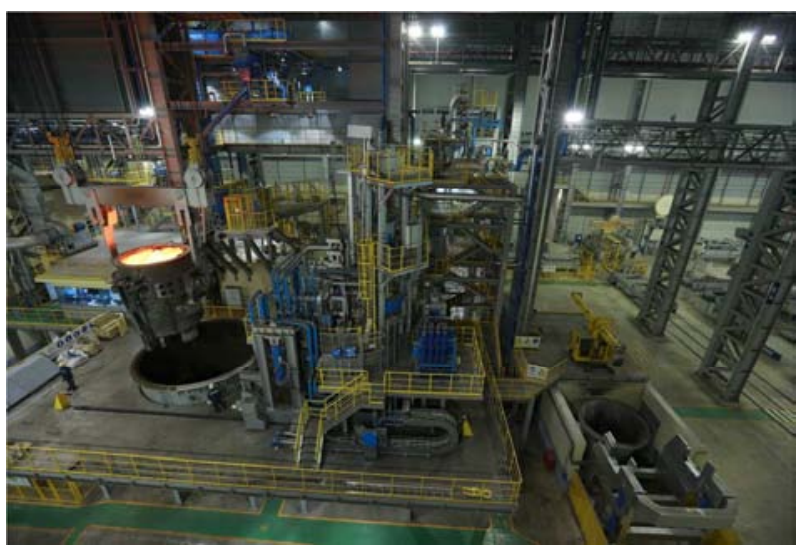

Figure 4. Vacuum Degassing / Vacuum Oxygen Decarburization.

\subsection{CC (Continuous Casting)}

Figure 5 shows $\mathrm{CC}$ facility utilized at Taewoong. The facility adopts full-curved type and three stands. Mould level control is performed by eddy current and Co- 60 radioactive and air-mist spray cooling is used at secondly cooling zone. Round bloom that has section size of $310 \mathrm{~mm}$ to $1,000 \mathrm{~mm}$ can be fabricated. The length of round bloom is $3,000 \mathrm{~mm}$ to $9,000 \mathrm{~mm}$ and limited to $6,000 \mathrm{~mm}$ with the section size of $1,000 \mathrm{~mm}$. Figure 6 shows manufactured round blooms.

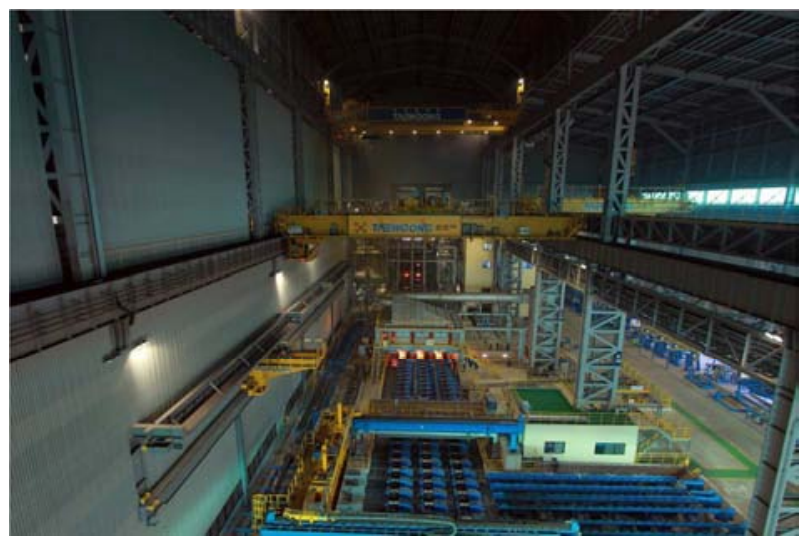

Figure 5. Continuous casting.

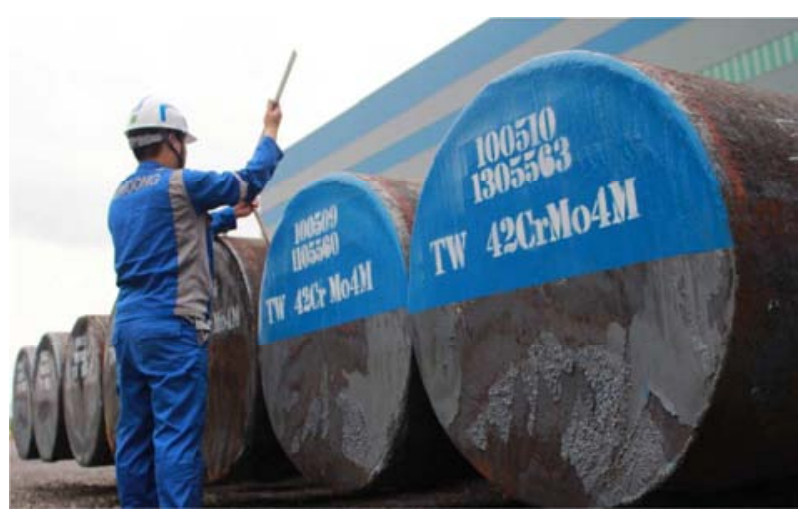

Figure 6. Manufactured round blooms.

\section{Hot Forging Process}

Taewoong is a forging manufacturer, specialized in the production of large size hot forged parts and manufacturing of large size round bloom enables increasing the competitiveness of the company. As shown in figure 7 (a) and (b), large size forging press and ring rolling mill are utilized to fabricate those products. In this study, tower flange was manufactured with the facilities and the $\varnothing 1,000$ round bloom. Figure 8 shows schematic diagram of flange forming process. Cutting, heating, forging, piercing and ring rolling will be sequentially, and the round bloom deforms to final target shape during the process $[5,6]$.

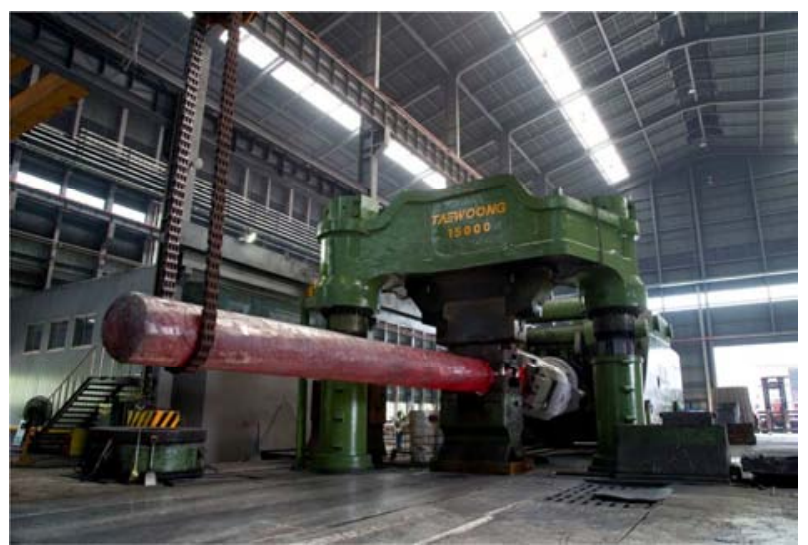

(a)

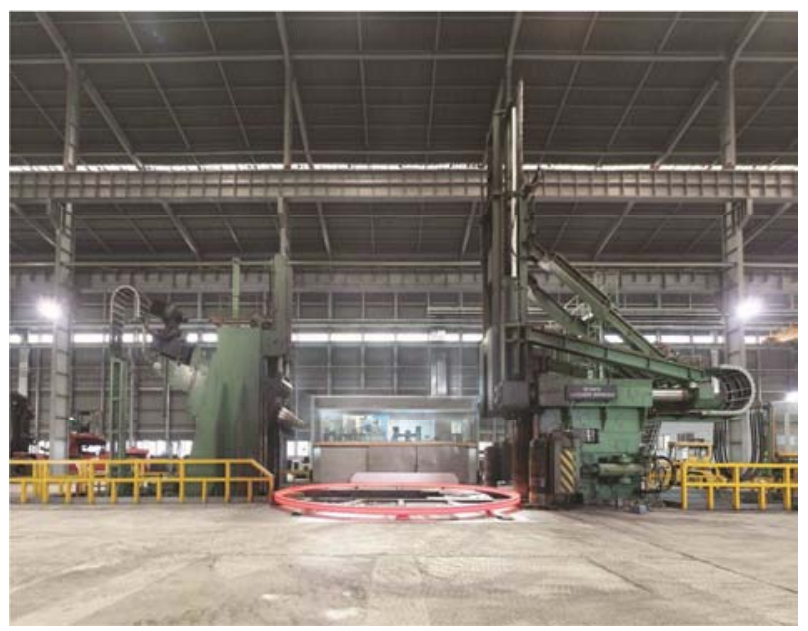

(b)

Figure 7. (a) 15,000 ton forging press, (b) Ø 9,500 ring rolling mill.

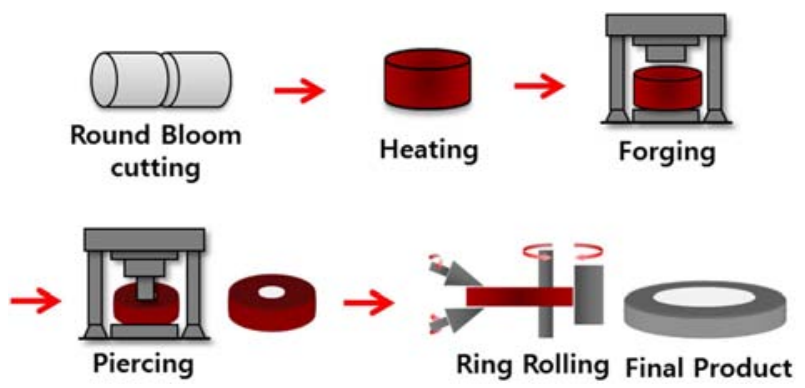

Figure 8. Schematic diagram of flange forming process.

Work sequence design was performed using FE analysis software and figure 9 shows optimal forging work sequence. 
Round bloom deforms to target shape during upsetting, punching and ring roll process. Figure 10 shows actual ring rolling process as designed optimal forging work sequence and the final product is shown in figure 11. As predicted in the finite element analysis, target shape is successfully fabricated using $\varnothing 1,000$ round bloom with high quality.

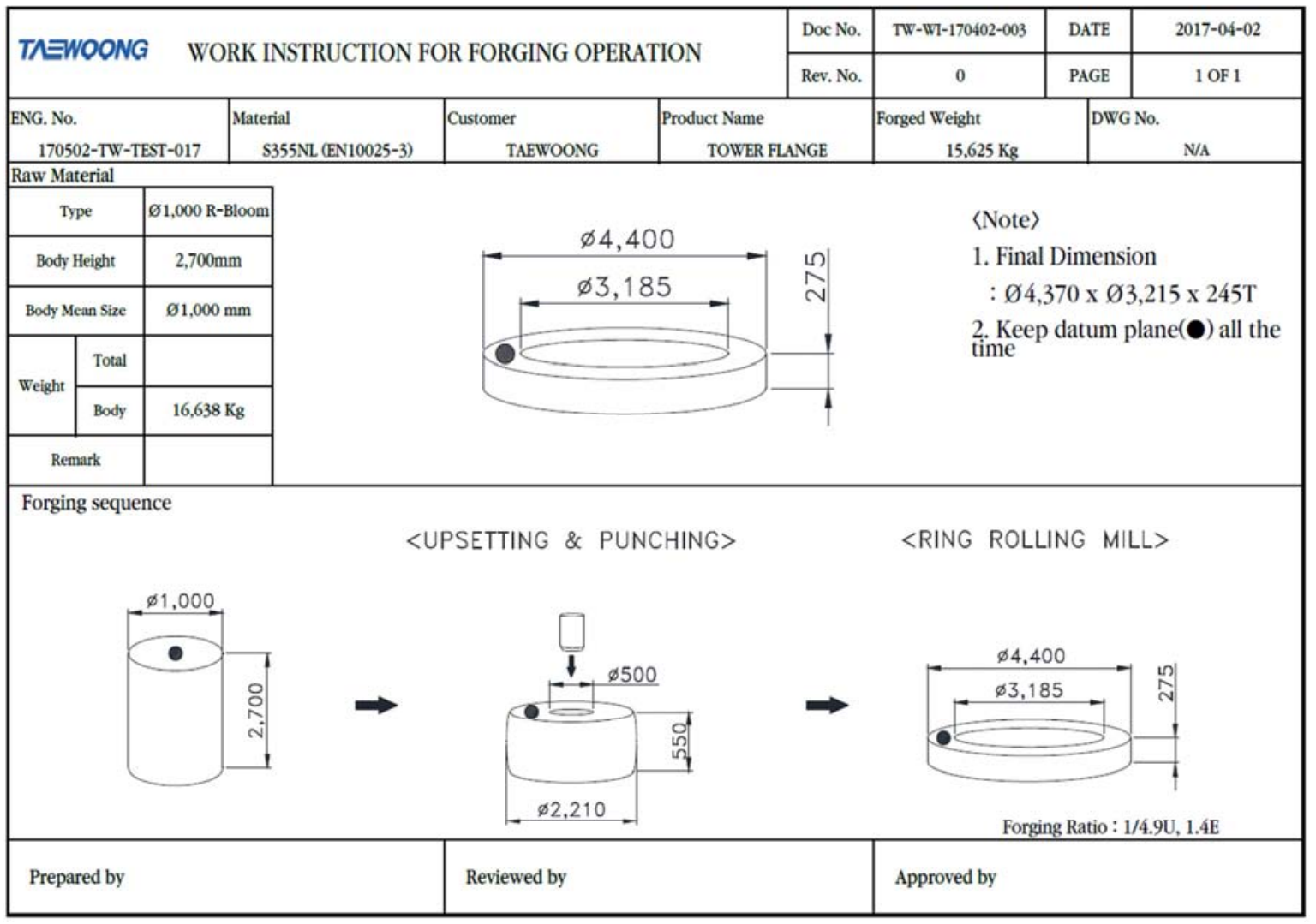

Figure 9. Optimal forging work sequence of flange forming process.
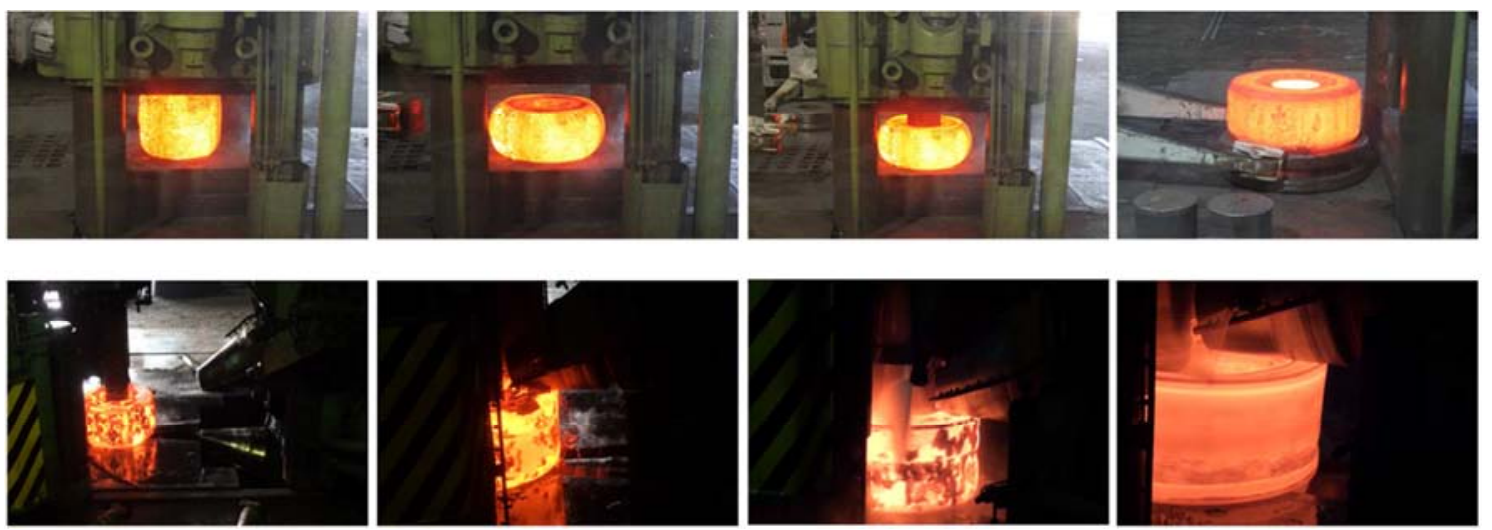

Figure 10. Flange hot forging process following the suggested work sequence.

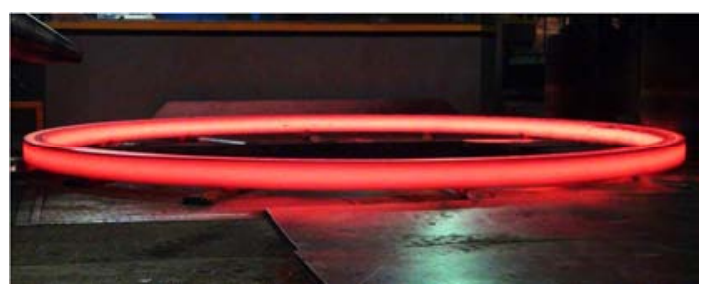

Figure 11. Ring rolled product manufactured with Ø 1,000 round bloom.

The main advantage of fabricating ring rolled products using round bloom is increase of recovery ratio of raw material compare to that of ingot. Normally, in ingot forging process, $15 \%$ of hot top and $5 \%$ of bottom part should be discarded. Round bloom has homogeneous properties with longitudinal direction, waste part can be reduced compare to ingot. Also, by removing discard process, the number of total process and processing time can be decreased.

\section{Conclusion}

Taewoong utilized facilities for continuous casting consists of EAF (Electric Arc Furnace), LF (Ladle Furnace), VD 
(Vacuum Degassing), VOD (Vacuum Oxygen Decarburization) and CC (Continuous Casting). Ø 1,000 large size round bloom was successfully manufactured and an attempt to fabricate a tower flange with the round bloom. Optimal forging work sequence was designed and target shape is successfully hot forged without any defects. By using round bloom, recovery ratio of raw material was increased compared to using ingot. Also, the number of total process and processing time was decreased. The results show utilized continuous cast facility gives opportunity to be a world competitive company, Taewoong.

\section{Acknowledgements}

This work was supported by Industrial Strategic Technology Development Program (10062473, Manufacturing of $\varnothing 1,000$ grade large diameter round bloom and development of high quality forged product using this round bloom) funded By the Ministry of Trade, Industry \& Energy (MOTIE, Korea).

\section{References}

[1] G. Zhau, L. Hau, D. H. Qian and H. X. Li, Effects of axial rolls motions on radial-axial rolling process for large-scale alloy steel ring with $3 \mathrm{D}$ coupled thermo-mechanical FEA, International Journal of Mechanical Sciences (2012, Volume 59) pp. 1-7.

[2] M. S. Joun, J. H. Chung and R. Shivpuri, An axisymmetric forging approach to preform design in ring rolling using a rigid-viscoplastic finite element method, International Journal of Machine Tools and Manufacture (1998, Volume 38), pp. 1183-1191.
[3] J. T. Yeom, J. H. Kim, N. K. Park, S. S. Choi and C. S. Lee, Ring-rolling design for a large-scale ring product of Ti-6Al4V alloy, Journal of Materials Processing Technology (2007, Volume 187-188), pp. 747-751.

[4] J. L. Song, A. L. Dowson, M. H. Jacobs, J. Brooks and I. Beden, Coupled thermo-mechanical finite-element modelling of hot ring rolling process, Journal of Materials Processing Technology (2002, Volume 121), pp. 332-340.

[5] K. Suresh, K. P. Rao, Y. V. R. K. Prasad, N. Hort and K. U. Kainer, Study of hot forging behavior of as-cast $\mathrm{Mg}-3 \mathrm{Al}$ $1 \mathrm{Zn}-2 \mathrm{Ca}$ alloy towards optimization of its hot workability. Materials \& Design (2014, Volume 57), pp. 697-704.

[6] V. Imayev, R. Gaisin, E. Gaisina, R. Imayev, H. J. Fecht and F. Pyczak, Effect of hot forging on microstructure and tensile properties of Ti-TiB based composites produced by casting. Materials Science and Engineering: A (2014, Volume 609), pp. 34-41.

[7] F. Chen, F. Ren, J. Chen, Z. Cui and H. Ou, Microstructural modeling and numerical simulation of multi-physical fields for martensitic stainless steel during hot forging process of turbine blade. The International Journal of Advanced Manufacturing Technology (2016 Volume 82), pp. 85-98.

[8] T. R. Prabhu, Simulations and Experiments of Hot Forging Design and Evaluation of the Aircraft Landing Gear Barrel Al Alloy Structure. Journal of Materials Engineering and Performance (2016, Volume 25), pp. 1257-1268.

[9] S. Casotto, F. Pascon, A. M. Habraken, S. Bruschi, Thermomechanical-metallurgical model to predict geometrical distortions of rings during cooling phase after ring rolling operations, International Journal of Machine Tools and Manufacture (2005, Volume 45), pp. 657-664.

[10] K. H. Kim, H. G. Suk and M. Y. Huh, Development of the profile ring rolling process for large slewing rings of alloy steels, Journal of Materials Processing Technology (2007, Volume 187-188), pp. 730-733. 